\title{
Concetta Cavallini, Essais sur la langue de Montaigne. Théories et Pratiques
}

\section{Filippo Fassina}

\section{Q OpenEdition}

1 Journals

\section{Edizione digitale}

URL: https://journals.openedition.org/studifrancesi/21126

DOI: 10.4000/studifrancesi.21126

ISSN: 2421-5856

\section{Editore}

Rosenberg \& Sellier

\section{Edizione cartacea}

Data di pubblicazione: 1 décembre 2019

Paginazione: 565

ISSN: 0039-2944

\section{Notizia bibliografica digitale}

Filippo Fassina, "Concetta Cavallini, Essais sur la langue de Montaigne. Théories et Pratiques», Studi Francesi [Online], 189 (LXIII | III) | 2019, online dal 01 mars 2020, consultato il 11 novembre 2021. URL: http://journals.openedition.org/studifrancesi/21126; DOI: https://doi.org/10.4000/studifrancesi. 21126

Questo documento è stato generato automaticamente il 11 novembre 2021.

\section{(c)}

Studi Francesi è distribuita con Licenza Creative Commons Attribuzione - Non commerciale - Non opere derivate 4.0 Internazionale. 


\title{
Concetta Cavallini, Essais sur la langue de Montaigne. Théories et Pratiques
}

\author{
Filippo Fassina
}

\section{NOTIZIA}

Concetta Cavallini, Essais sur la langue de Montaigne. Théories et Pratiques, Bari, Cacucci

Editore, 2019, $210 \mathrm{pp}$.

1 Una delle caratteristiche più interessanti dei testi di Montaigne è senza dubbio la lingua, sia dal punto di vista dell'organizzazione sintattica, sia da quello dell'argomentazione concettuale. L'A. chiarisce fin dall'inizio che sarebbe riduttivo parlare solo di maîtrise rhétorique, in quanto si tratta di una questione più profonda che investe l'intero mondo concettuale di Montaigne. Manca, in realtà, a livello di studi, una riflessione completa e articolata sulla sua lingua e tutti gli approcci adottati sono limitati e hanno prodotto articoli sparsi, ma non del tutto esaustivi. Per offrire invece un lavoro completo, è necessaria, in primo luogo, un'analisi dei manoscritti: la frammentazione e la varietà linguistica sono tali che, per averne un'idea precisa, si deve fare riferimento oltre che alle varie edizioni degli Essais $(1580,1582,1588)$, anche all'apporto degli editori, dei segretari, dei copisti, dei bibliotecari, i cui interventi possono aver influito sul testo finale, anche solo a livello di paginazione. Un progetto di tale portata, come si vede, non può limitarsi a uno studio teorico, ma deve tenere conto necessariamente della pratique de la langue, che peraltro in Montaigne non è mai univoca, ma è in continuo mutamento e soggetta a correzioni, modifiche, ampliamenti. L'A. parte dunque dal presupposto che si debbano analizzare i testi di Montagne dal punto di vista della scrittura, dello stile, della retorica, del linguaggio e, solo in una fase finale, della lingua nella sua complessità, poiché tutte le parole hanno un legame chiaro fra loro e sono disposte non a caso, ma in maniera da ottenere sempre un effetto particolare. Dal momento che il contesto linguistico e normativo in cui opera 
Montaigne è alquanto complesso, per via del percorso di standardizzazione che la lingua francese sta intraprendendo, definire in maniera univoca i concetti di lingua, stile e retorica è pressoché impossibile, ma l'A. molto puntualmente sottolinea che è sua intenzione proporre delle riflessioni e analizzare una serie di tratti caratteristici della lingua montaigniana, attraverso un procedimento à rebours, cioè una diachronie renversée. Nella prima parte del volume (pp. 1-49) vengono dunque affrontati i problemi della ricezione del testo di Montaigne e delle possibili letture, evitando di dare una visione semplicistica e predefinita dell'opera, ma cercando di tenere conto, attraverso uno studio testuale, delle pratiche linguistiche. La seconda parte (pp. 51-167) offre invece un'analisi dei testi, partendo da quelli in cui l'autore fornisce i criteri utilizzati nella scrittura e alcune parole chiave utili per decifrare il suo rapporto con la lingua. Inoltre, viene messa in evidenza la grande abilità di Montaigne nell'uso della retorica, abilità acquisita anche grazie alla lettura delle arts poétiques e dei trattati cinquecenteschi. La seconda parte del saggio è dunque dedicata quasi interamente al testo degli Essais, di cui vengono forniti numerosi esempi, analizzati sia dal punto di vista lessicale, sia da quello dell'uso della lingua e della forma. Nell'indubbia complessità e finezza di questo lavoro, lo studio che viene qui presentato conduce a interessanti conclusioni su come comprendere la lingua di Montaigne, il suo stile e la sua scrittura. In primo luogo, non bisogna compiere l'errore di leggere gli Essais in maniera frammentaria, come spesso si è portati a fare dall'impianto stesso dell'opera. In secondo luogo, è fondamentale tenere conto del fatto che la lingua di Montaigne, come del resto la struttura stessa degli Essais, è in continuo cambiamento ed evoluzione, si adatta e si modifica in base ai ragionamenti e agli argomenti: si tratta di una chiara scelta di rifiuto della regolarità a favore del mélange. Il risultato è, come ha ben sottolineato l'A., un testo libero da vincoli, irregolare sul quale Montaigne torna spesso per correggere, modificare, aggiungere. Ma è proprio in questa rottura con la linearità e la regolarità del passato che sta la genialità di Montaigne e la ricchezza della sua lingua, come ben evidenzia l'eccellente studio di Concetta Cavallini. 